\title{
Experimental COP evaluation of a 65-litre household refrigerator running with $\mathrm{R600a}$
}

\author{
Saleh J. Alqaisy ${ }^{1,4}$, Kamel S. Hmood ${ }^{1,2}$, Mahdi Hatf Kadhum Aboaltabooq ${ }^{3}$ Valentin \\ Apostol $^{* 1}$, Horatiu Pop ${ }^{1}$, Jamal Al Douri, ${ }^{1,4}$, and Viorel Bădescu ${ }^{5}$ \\ ${ }^{1}$ Dept. of Applied Thermodynamics, Engines, Thermal and Refrigeration Equipment, University \\ Politehnica of Bucharest, Romania \\ ${ }^{2}$ University of Babylon, Iraq \\ ${ }^{3}$ Al-Furat Al-Awsat Technical University, Technical College Najaf, Iraq \\ ${ }^{4}$ University of Technology, Iraq \\ ${ }^{5}$ Candida Oancea Institute, Polytechnic University of Bucharest, Spl. Independentei 313, Bucharest \\ 060042, Romania.Romania
}

\begin{abstract}
A household refrigerator is a major energy consumer in all homes. The paper aims to evaluate based, on experimental data, the COP of a 65-liter household refrigerator operating with R600a. The main components and instrumentation of the experimental setup are presented. A mathematical model based on the energy balance of the refrigerated enclosure is developed in order to evaluate the COP. Three experimental data sets have been obtained in quasi-steady-state operating conditions. The results point out that the compressor power absorbed from the grid was 60 [W]. The maximum value for the cooling capacity is $81.73 \mathrm{~W}$ while the minimum value is $80.24 \mathrm{~W}$. In terms of COP, the maximum value obtained is 1.362 , while the minimum one is 1.337 . The COP values obtained in the present study are in good agreement with the ones displayed by the manufacturer in the compressor datasheet. Future development is discussed.
\end{abstract}

Keywords: COP, R600a, household refrigerator

\section{Introduction}

It is hard to imagine modern residential life without the advantages offered by artificial cooling. Artificial cooling in residential applications can be divided into two main categories, namely food preservation and air conditioning. The most affordable and widely used mean for food preservation is the household refrigerator (HR). The number of HR worldwide is 1 to 1.6 billion [1,2] consuming about $6 \%$ of the electricity generated worldwide [2]. The estimated lifetime of an HR is around $10-20$ years [3] and it is accountable for about 32 to $50 \%$ of the total energy consumption of a residence $[4,5]$. Given the high number of HRs worldwide and the associated energy consumption, improving their energy efficiency becomes of interest. The most commonly used indicator for the energy efficiency of HRs is the coefficient of performance (COP). As presented below, a key component in the struggle to achieve lower energy consumption is the type of refrigerant being used [6]. Since $1^{\text {st }}$ of January 2015, in the field of household refrigerators

\footnotetext{
*Corresponding author: valentin.apostol@magr.ro
} 
and freezers, refrigerants having a Global Warming Potential (GWP) higher than 150 are prohibited [7]. In this context, R600a, R290 and their mixtures have been proposed and used since, as alternative refrigerants. A brief literature survey regarding the use of R600a, R290 and their mixtures, correlated with the COP, is presented below.

The ambient temperature and the type of refrigerant are among the parameters that have a high influence on the COP of HR. In this regard, Raveendran and Sekhar [8] conducted a study, in a tropical area, on a $190 \mathrm{~L}$ refrigerator, considering an ambient temperature of 32 ${ }^{\circ} \mathrm{C}$. The authors concluded that using a proper mixture of R600a and R290 with $54.8 \%$ and $45.2 \%$ mass fractions, respectively, leads to a $5.9 \%$ reduction in energy consumption and an $8.9 \%$ improvement in the COP, compared to the case when R134a is used as a refrigerant. Saran et al [9] concluded from their experimental research, that mixing R600a and R290, in $40 \%$ and $60 \%$ mass fractions, respectively, leads to higher COP and lower energy consumption, compared to the other mixing ratios. Hmood et al. [10] explained, in their analysis, that the R600a refrigerant leads to a 3\% higher COP compared to R134a. The study was carried out for a small scale refrigerator. A drawback of R600a is its flammability, which determines the need to search for eco-friendly, energy-efficient and high-performance refrigerants [11]. Cho et al. [12] developed a simulation model and compared it with a practical experiment on household refrigerator-freezers working with R600a. The authors concluded that the length and the diameter of the hot-wall condenser pipe has a direct influence on the COP. The refrigerant charge, energy consumption and COP decrease with the reduction of the length and diameter of the hot-wall condenser pipe and vice versa. Abou-Ziyan and Fatouh [13] experimented on a household refrigerator comparing the case of using R134a and the case of using R600, R600a and R290 mixtures. The best mixing ratio proved to be $13.4 \%$ R600a, $26.6 \%$ R600a and $60 \%$ R290. For this particular mixing ratio, the authors have modified the refrigerant charge in the range of 30 , 40, 50, 60, and $70 \mathrm{~g}$. Different capillary tube (CT) lengths have also been considered in the range of 4, 4.5, 5, 5.5 and $6 \mathrm{~m}$. The authors concluded that, $5.5 \mathrm{~m} \mathrm{CT}$ length and $70 \mathrm{~g}$ of refrigerant will lead to a $3 \%$ higher COP than in case of R134a.

In this context, the paper aims to evaluate experimentally, the COP of a small-scale refrigerator operating with R600a. The COP values are evaluated using data obtained from a specific experimental setup. A brief description of the experimental setup is given in Section 2. Section 3 presents the mathematical model used for COP evaluation. Experimental input data and results are presented in section 4. Finally, in Section 5, the main conclusions and development targets are presented.

\section{Experiment setup}

An overview image of the experimental setup is presented in Fig. 1. Basically, the experimental setup is comprised of a small refrigerator, measurement instruments and an automation/control panel. 


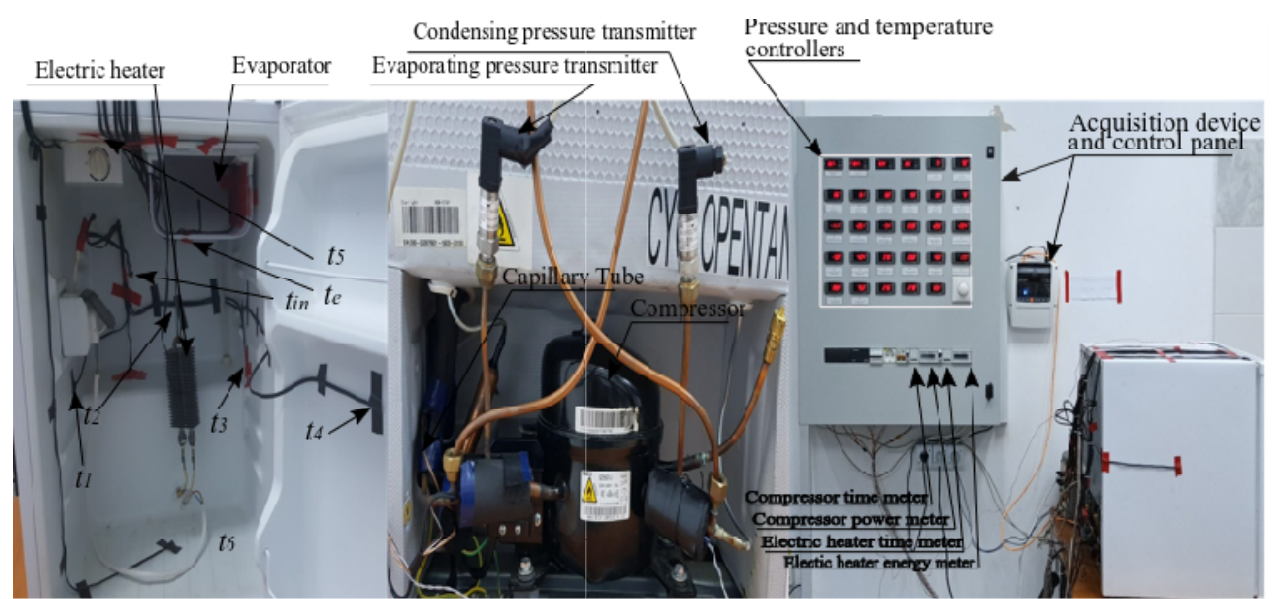

(a) (b) (c)

Fig.1. Overview image of the experimental setup: a. Front view, b. Back view, c. Side view

The refrigerator is a hot-wall condenser (HWC) MBM-67AP type, having $65 \mathrm{~L}$. The dimensions of the refrigerator are $0.50 \times 0.50 \times 0.60 \mathrm{~m}$. The refrigerant used is R600a. The evaporator is a roll bond type made of coated aluminum (see Fig. 1, front view). The compressor is a hermetic reciprocating compressor (HRC) (see Fig. 1 back view). Hot wallcondenser means, that the condenser is placed inside the right, upper and left walls of the refrigerator, being in contact with the outer metal sheet. From the outer metal sheet to the surroundings, the heat is transfer by natural convection. The CT has a length of $2.26 \mathrm{~m}$, an inner diameter of $0.5 \mathrm{~mm}$ and an outer diameter of $1.2 \mathrm{~mm}$ (see Fig. 1, back view). The heat source is simulated using a $150 \mathrm{~W}$ adjustable static electric heater (see Fig. 1, front view).

The experimental setup is instrumented with temperature and pressure sensors. For temperature measurements, NTC thermistor sensors are used. In order to conduct the energy balance for the refrigerated enclosure, the temperature of each wall is measured. In Fig. $1, t_{1}$ is the temperature of the left wall, $t_{2}$ is the temperature of the back wall, $t_{3}$ is the temperature of the right wall, $t_{4}$ is the temperature of the door wall, $t_{5}$ is the temperature of the top wall, $t_{6}$ is the temperature of the bottom wall. The evaporator wall temperature $t_{e}$, the temperature of the air inside the refrigerated enclosure $t_{\text {in }}$ and the ambient temperature $\mathrm{t}_{\mathrm{amb}}$, are also measured. The condensing $\left(p_{c o n}\right)$ and evaporating $\left(p_{e v}\right)$ pressures are measured using pressure transducers (see Fig. 1 back view). The temperature sensors and the pressure transducers are connected to the corresponding controllers, mounted in the automation and control panels (see Fig. 1 side view).

The experimental setup is also fitted with a power adjustment device for the static electric heater, energy and time meters for the compressor and the static electric heater (see Fig. 1 side view).

\section{The mathematical model for the COP evaluation}

The mathematical model for COP evaluation is based on the energy balance of the refrigerated enclosure. A schematic of the refrigerated enclosure corresponding to the experimental setup is given in Fig. 2. 


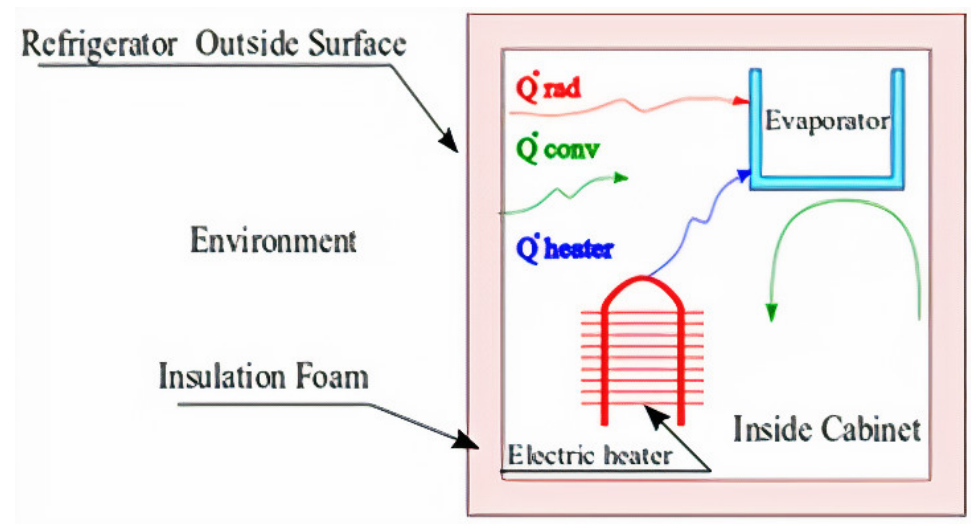

Fig. 2. Energy balance of the refrigerated enclosure

The energy balance of the refrigerated enclosure can be described by the following equation:

$$
\dot{Q}_{o}=\dot{Q}_{\text {rad }}+\dot{Q}_{\text {conv }}+\dot{Q}_{\text {Heater }}
$$

Where: $\dot{Q}_{o}$ is the cooling capacity of the refrigerator [W]; $\dot{Q}_{\text {rad }}$ is the heat transferred through radiation from the enclosure walls to the evaporator $[\mathrm{W}] ; \dot{Q}_{\text {conv }}$ is the heat transferred through free convection from the walls to the air inside the refrigerated enclosure [W] and $\dot{Q}_{\text {Heater }}$ is the heat transferred through convection and radiation from the electric heater to the air inside and then to the evaporator [W].

The heat transferred through radiation from the enclosure walls to the evaporator is the sum of the radiative heat fluxes rejected from each wall and received by each wall of the evaporator. The heat flux transferred through radiation can be computed based on the general formula presented by Welty et al, [14]:

$$
\dot{Q}_{\text {rad }}=\frac{\sigma\left(T_{w}^{4}-T_{e}^{4}\right)}{\frac{\left(1-\varepsilon_{w}\right)}{A_{w} \varepsilon_{w}}+\frac{1}{A_{w} F_{w-e}}+\frac{1-\varepsilon_{e}}{A_{e} \varepsilon_{e}}}
$$

In eq. (2) $\sigma=5.67 \cdot 10^{-8} \mathrm{~W} /\left(\mathrm{m}^{2} K^{4}\right)$ is the Stefan Boltzmann constant, $A_{w}\left[\mathrm{~m}^{2}\right]$ is the area of the enclosure wall for which the rejected radiative heat flux is computed, $A_{e}\left[\mathrm{~m}^{2}\right]$ is the area of the evaporator wall which receives the radiative heat flux, $T_{w}[\mathrm{~K}]$ is the temperature of the enclosure wall, $T_{e}[\mathrm{~K}]$ is the temperature of the evaporator wall, $\varepsilon_{w}$ is the emissivity factor of the enclosure walls (for the present study the value of $\varepsilon_{w}$ has been considered to be 0.95 corresponding to white plastic materials), $\varepsilon_{e}$ is the emissivity factor of the evaporator walls (or the present study the value of $\varepsilon_{e}$ has been considered to be 0.88 corresponding to white painted aluminum materials) $[15,16]$ and $F_{w-e}$ is the view factor which takes into consideration the relative position of the enclosure wall to the evaporator wall. The view factor can be computed according to Lienhard [17].

The heat flux received by the air inside the enclosure from the refrigerator walls through free convection can be computed using the following relationship: 


$$
\dot{Q}_{\text {conv }}=h \cdot A_{w} \cdot\left(t_{w}-t_{\text {air }}\right)
$$

In eq. (3), $h\left[\mathrm{~W} /\left(\mathrm{m}^{2} \mathrm{~K}\right)\right]$ is the natural convective heat transfer coefficient, $A_{w}\left[\mathrm{~m}^{2}\right]$ is the area of the refrigerator wall which rejects the convective heat flux, $t_{\text {air }}\left[{ }^{\circ} \mathrm{C}\right]$ is the temperature of the air inside the refrigerated enclosure and $t_{w}\left[{ }^{\circ} \mathrm{C}\right]$ is the temperature of the refrigerator wall. Eq. (3) is applied for each individual wall of the refrigerator.

The convective heat transfer coefficient can be determined as follows $[18,19]$ :

$$
h=\frac{N u \cdot k}{L}
$$

Where $N u$ stands for the Nusselt number, $k[\mathrm{~W} /(\mathrm{m} \mathrm{K})]$ is the thermal conductivity of the air inside the refrigerated enclosure [20] and $L[\mathrm{~m}]$ is the characteristic length of the refrigerator wall rejecting the convective heat flux.

The heat flux transferred from the refrigerator wall to the air inside the enclosure takes place by means of natural convection. Natural convection can be characterized through the Rayleigh number:

$$
R a=G r \cdot P r=\frac{g \cdot \beta \cdot \Delta T \cdot L^{3}}{\alpha \cdot v}
$$

Where: $\beta[1 / \mathrm{K}]$ is the thermal expansion coefficient, $g\left[\mathrm{~m} / \mathrm{s}^{2}\right]$ is the gravitational acceleration, $\Delta T[\mathrm{~K}]$ is the temperature difference between the refrigerator wall and the air inside the refrigerator enclosure, $\alpha\left[\mathrm{m}^{2} / \mathrm{s}\right]$ is the thermal diffusivity and $v\left[\mathrm{~m}^{2} / \mathrm{s}\right]$ is the kinematic viscosity.

The Nu number is computed accordingly, as presented next.

As it can be seen from Fig. 1 front view, the refrigerator has vertical and horizontal walls. For the present study, the refrigerator walls have been considered vertical and horizontal plates. For vertical plate walls, if the Rayleigh number $R a \leq 10^{9}$, the Nu number can be computed as $[14,17,21]$ :

$$
N u=0.68+0.670 \cdot R a^{1 / 4} \cdot\left[1+\left(\frac{0.492}{P r}\right)^{9 / 16}\right]^{-(4 / 9)}
$$

For vertical plate walls, if the Rayleigh number $R a>10^{9}$, the Nu number can be computed as [22,23]:

$$
N u=\left[0.825+\frac{0.387 \cdot R a^{1 / 6}}{\left[1+\left(\frac{0.492}{P r}\right)^{9 / 16}\right]^{8 / 27}}\right]^{2}
$$

The heat transfer from the horizontal walls of the refrigerator has been calculated applying Eq. (8), as follows:

$$
\alpha_{\text {hor }, \text { down }}=0.27 \cdot R a^{0.25} \cdot \frac{k}{L}
$$


Eq. (8) is applied for $10^{5}<\mathrm{Ra}<10^{10}$ and $\mathrm{L}$ is the characteristic length of the horizontal plate walls of the refrigerator.

The heat flux received from the static heater can be computed as:

$$
\dot{Q}_{\text {Heater }}=\frac{E_{\text {Heater }}^{\text {final }}-E_{\text {Heater }}^{\text {initial }}}{\tau_{\text {operation }}^{\text {final }}-\tau_{\text {operation }}^{\text {initial }}}
$$

In Eq. (9), $E_{\text {Heater }}^{\text {initial }}[\mathrm{kWh}]$ is the electric heater energy meter reading at the beginning of the operation time period, $E_{\text {Heater }}^{\text {final }}[\mathrm{kWh}]$ is the reading of the electric heater energy meter at the end of the operation time period $[\mathrm{kWh}] ; \tau_{\text {operation }}^{\text {initial }}[\mathrm{h}]$ is the reading of the time meter at the beginning of the operation time period and $\tau_{\text {operation }}^{\text {final }}[\mathrm{h}]$ is the reading of the time meter at the end of the operation time period.

The real COP of the household refrigerated used in the present study is determined as [24]:

$$
C O P=\frac{\dot{Q}_{o}}{P}
$$

Where $\mathrm{P}[\mathrm{kW}]$ is the power absorbed by the compressor from the electric grid and it can be computed as:

$$
P=\frac{E_{\text {Comp }}^{\text {final }}-E_{\text {Comp }}^{\text {initial }}}{\tau_{\text {operation }}^{\text {final }}-\tau_{\text {operation }}^{\text {initial }}}
$$

In Eq. (11), $E_{\text {Comp. }}^{\text {initial }}[\mathrm{kWh}]$ is the compressor energy meter reading at the beginning operation time period and $E_{\text {Comp }}^{\text {final }}[\mathrm{kWh}]$ is the compressor energy meter reading at the end of the operation time period.

Using the mathematical model described before, in the next section, experimental input data is presented. Results are presented in a tabular manner and commented on.

\section{Experimental input data and results}

The experimental data used in the present paper is presented in Table 1 and Table 2 for three individual tests. Table 1 presents the experimental data regarding temperatures and pressures while Table 2 shows the energy consumption of the electric heater, energy consumption of the compressor and time meter readings at the beginning and the end of the corresponding test, respectively.

Table 1. Experimental input data for measured temperatures and pressures

\begin{tabular}{|l|c|c|c|c|c|c|c|c|c|c|c|}
\hline & $\begin{array}{c}t_{I} \\
{\left[{ }^{\circ} \mathrm{C}\right]}\end{array}$ & $\begin{array}{c}t_{2} \\
{\left[{ }^{\circ} \mathrm{C}\right]}\end{array}$ & $\begin{array}{c}t_{3} \\
{\left[{ }^{\circ} \mathrm{C}\right]}\end{array}$ & $\begin{array}{c}t_{4} \\
{\left[{ }^{\circ} \mathrm{C}\right]}\end{array}$ & $\begin{array}{c}t_{5} \\
{\left[{ }^{\circ} \mathrm{C}\right]}\end{array}$ & $\begin{array}{c}t_{6} \\
{\left[{ }^{\circ} \mathrm{C}\right]}\end{array}$ & $\begin{array}{c}t_{e} \\
{\left[{ }^{\circ} \mathrm{C}\right]}\end{array}$ & $\begin{array}{c}t_{i n} \\
{\left[{ }^{\circ} \mathrm{C}\right]}\end{array}$ & $\begin{array}{c}t_{\text {amb }} \\
{\left[{ }^{\circ} \mathrm{C}\right]}\end{array}$ & $\begin{array}{c}p_{e v} \\
{[\mathrm{bar}]}\end{array}$ & $\begin{array}{c}p_{\text {con }} \\
{[\mathrm{bar}]}\end{array}$ \\
\hline Test 1 & 9.6 & 10.4 & 9.1 & 8.5 & 8.6 & 7.4 & -26.9 & 5.7 & 25 & 0.507 & 7.36 \\
\hline Test 2 & 10.2 & 11.3 & 9.4 & 9.1 & 9.1 & 8.0 & -25.6 & 6.4 & 26 & 0.514 & 7.52 \\
\hline Test 3 & 12.5 & 13.8 & 12.9 & 11.5 & 12.9 & 10.3 & -24.5 & 8.6 & 21 & 0.518 & 7.14 \\
\hline
\end{tabular}


Table 2. Experimental data for energy consumption and time meter readings

\begin{tabular}{|c|c|c|c|c|c|c|c|}
\hline & $\begin{array}{c}E_{\text {Heater }}^{\text {initial }} \\
{[\mathrm{kWh}]}\end{array}$ & $\begin{array}{c}E_{\text {Heater }}^{\text {final }} \\
{[\mathrm{kWh}]}\end{array}$ & $\begin{array}{c}E_{\text {Comp. }}^{\text {initial }} \\
{[\mathrm{kWh}]}\end{array}$ & $\begin{array}{c}E_{\text {Comp. }}^{\text {final }} \\
{[\mathrm{kWh}]}\end{array}$ & $\begin{array}{c}\tau_{\text {operation }}^{\text {initial }} \\
{[\mathrm{h}]}\end{array}$ & $\begin{array}{c}\tau_{\text {operation }}^{\text {final }} \\
{[\mathrm{h}]}\end{array}$ & $\begin{array}{c}\text { Operation } \\
\text { total } \\
\text { Time }[\mathrm{h}]\end{array}$ \\
\hline Test 1 & 34.46 & 34.57 & 16.63 & 16.75 & 504.2 & 506.2 & 2.0 \\
\hline Test 2 & 34.68 & 34.79 & 16.90 & 17.02 & 508.5 & 510.5 & 2.0 \\
\hline Test 3 & 35.50 & 35.61 & 17.85 & 17.97 & 425.6 & 527.6 & 2.0 \\
\hline
\end{tabular}

The three experimental data sets presented in Table 1 and Table 2 correspond to a quasisteady-state operation of the experimental setup. To reach the quasi-steady-state operation of the experimental setup, the compressor was programmed to turn off at $t \_c o m p \_o f f=5{ }^{\circ} \mathrm{C}$ and turn on at $t \_c o m p \_o n=12{ }^{\circ} \mathrm{C}$ while the electric heater was programmed to turn off at t_heater_off $=10^{\circ} \mathrm{C}$ and turn on at $t$ heater_on $=7{ }^{\circ} \mathrm{C}$. The quasi-steady-state operation can be reached by adjusting the power of the static heater to match the cooling capacity of the compressor. Several experiments have been carried out to determine the quasi-steady-state condition, before the experiment tests presented in Table 1 and Table 2. As a general remark, at least three hours are required for each experimental data set, from which one hour to reach the quasi-steady-state and two hours to experiment with quasi-steady-state conditions. After a long operation time, the compressor will heat up and its efficiency will decrease leading to a reduction of its cooling capacity. After three hours, the cooling capacity of the compressor decreases and thus the power of the heat source should be adjusted accordingly. For the present experimental study, the ability to adjust the power of the heat source to match the cooling capacity of the compressor is limited and thus the maximum operation time in quasi-steady-state conditions has been limited to three hours.

Using the experimental data presented in Table 1 and Table 2, the mathematical model presented in Section 2 is applied. As it can be seen, the experimental data presented in Table 1 and Table 2 display close values for all three experimental tests.

The results obtained in the present study, for the three data sets, regarding the compressor power P [W], electric heater heat flux $\dot{\mathrm{Q}}_{\text {Heater }}[\mathrm{W}]$, heat flux transferred through radiation from the enclosure walls to the evaporator $\dot{\mathrm{Q}}_{\mathrm{rad}}[\mathrm{W}]$, heat flux transferred through natural convection from the enclosure inside walls to the air inside $\dot{\mathrm{Q}}_{\text {conv }}[\mathrm{W}]$, cooling capacity $\quad \dot{\mathrm{Q}}_{\mathrm{o}}[\mathrm{W}]$ and COP are presented in Table 4.

Table 4. Results

\begin{tabular}{|c|c|c|c|c|c|c|}
\hline & $\begin{array}{c}\mathrm{P} \\
{[\mathrm{W}]}\end{array}$ & $\begin{array}{c}\dot{\mathrm{Q}}_{\text {Heater }} \\
{[\mathrm{W}]}\end{array}$ & $\begin{array}{c}\dot{\mathrm{Q}}_{\text {rad }} \\
{[\mathrm{W}]}\end{array}$ & $\begin{array}{c}\dot{\mathrm{Q}}_{\text {conv }} \\
{[\mathrm{W}]}\end{array}$ & $\begin{array}{c}\dot{\mathrm{Q}}_{\mathrm{o}} \\
{[\mathrm{W}]}\end{array}$ & COP \\
\hline Test 1 & 60.0 & 55.0 & 12.56 & 13.39 & 80.95 & 1.349 \\
\hline Test 2 & 60.0 & 55.0 & 12.51 & 12.73 & 80.24 & 1.337 \\
\hline Test 3 & 60.0 & 55.0 & 13.22 & 13.51 & 81.73 & 1.362 \\
\hline
\end{tabular}

From Table 4 it can be noticed that the compressor power absorbed from the grid, for the three tests, is constant and has the value of 60 [W]. The power absorbed by the static electric heater from the grid, which is equal to the heat flux released to the air inside the refrigerated enclosure and then to the evaporator, was 55 [W]. The maximum value, among the three data sets, obtained for the cooling capacity is 81.73 [W] while the minimum value is 80.24 [W]. The cooling capacity of the small scale refrigerator used in this study according to the manufacturer data sheet is 85 [W][25]. The maximum and minimum values obtained for the cooling capacity are very close. In terms of COP, the highest value obtained, among the three data sets, is 1.362 and the lowest one is 1.337 . The highest and 
lowest values for the COP are close. The COP for the compressor displayed by the manufacturer in the datasheet [25] is 1.37 . The values for the cooling capacity and COP displayed by manufacturer are in good agreement with the values obtained in the present work, especially that the three experimental tests have been conducted in non-standard conditions.

\section{Conclusions}

The paper presents the results obtained for the experimental COP evaluation carried out on a small scale, 65-liter refrigerator, operating with R600a. A brief description of the experimental setup is given. A mathematical model for the COP evaluation, based on the energy balance of the refrigerated enclosure, is presented. The mathematical model has been applied for three experimental data sets obtained for quasi-steady-state operating conditions. The results point out that the compressor power absorbed from the grid it is 60.0 [W]. The power absorbed from the grid by the electric heater is approximately $55.0 \mathrm{~W}$. The maximum value, obtained for the cooling capacity is 81.73 [W] while the minimum value is 80.24 [W]. The cooling capacity of the small scale refrigerator used in this study according to the manufacturer data sheet is 85 [W]. The results obtained for the COP show that the maximum value obtained is 1.362 , while the minimum one is 1.337 . The COP for the compressor displayed by the manufacturer in the datasheet is 1.37 . There is good agreement between the results obtained in the present study and the data given by the manufacturer.

Future development involves a modification of the experimental setup in order to better match the cooling capacity of the compressor with the power of the electric heater. This modification will enable tests conducted for a longer time period in quasi-steady-state operating conditions.

\section{References}

1. K. Liang, Energy 151, 324-331 (2018)

2. L. Harrington, L. Aye, B. Fuller, Appl. Energy 211, 346-357 (2018)

3. M. Fatouh, H. Abou-Ziyan, Appl. Therm. Eng. 145 14-26 (2018)

4. A.E. Gürel, Ü. Agbulut, A. Ergün, I. Ceylan, Eng. Sci. Technol. an Int. J. 23365$372(2020)$

5. [H. Jin, Z. Sun, J. Gu, Y. Huang, X. Wang, Q. Zhang, X. Shen, Measurement 157 107654 (2020)

A. Pirvaram, S.M. Sadrameli, L. Abdolmaleki, Energy 181, 321-330 (2019)

A. Maiorino, R. Llopis, M.G. Del Duca, C. Aprea, Int. J. Refrig. 117, 132-139 (2020)

6. P. Saji Raveendran, S. Joseph Sekhar, Appl. Therm. Eng. 179, 115684 (2020)

7. T.S. Pilla, P.K.G. Sunkari, S.L. Padmanabhuni, S.S. Nair, R.S. Dondapati, Energy Procedia. 109, 113-121 (2017)

8. [K.S. Hmood, H. Pop, V. Apostol, A.Q. Ahmed, Am. Sci. Res. J. Eng. Technol. Sci. 35, 251-265 (2017)

9. S. Choi, U. Han, H. Cho, H. Lee, Appl. Therm. Eng. 132, 560-574 (2018)

10. W. Cho, D.S. Jang, S.H. Lee, S. Yun, Y. Kim, Int. J. Refrig. 117, 295-306 (2020)

11. H. Abou-Ziyan, M. Fatouh, Appl. Therm. Eng. 129, 446-462 (2018)

12. J.R. Welty, G.L. Rorrer, D.G. Foster, Fundamentals of Momentum, Heat, and Mass Transfer, (Sixth Edit. United States of America: John Wiley \& Sons, 2015)

13. A.A. Imran, H.M. Jafal, J. Eng. Dev. 13, 1-16 (2009) 
14. [R.S. Espíndola, J. Boeng, F.T. Knabben, C.J.L. Hermes, Int. J. Refrig. 114, 10-18 (2020)

15. J.H. Lienhard, A Heat Transfer Textbook (Fifth Edit. Phlogiston Press Cambridge, Massachusetts, U.S.A, 2019)

16. Y.A. Cengel, Heat and Mass Transfer (SI Units) A Practical Approach (Third Edit. United States of America: McGraw-Hill Education, 2006)

17. D. Azzouzi, M. Kelkouli, F. Amaryoucef, Appl. Therm. Eng. 122, 528-534 (2017)

18. R.S. Espíndola, F.T. Knabben, C. Melo, C.J.L. Hermes, Int. J. Refrig. 110, 262$267(2020)$

19. F.P. Incropera, D.P. DeWitt, T.L. Bergman, A.S. Lavine, Fundamentals of Heat and Mass Transfer (Sixth Edit. United States of America: John Wiley \& Sons, Inc, 2007)

20. J.K. Gupta, M. Ram Gopal, Int. J. Refrig. 31, 979-988 (2008)

21. Y. A. Çengel, A.J. Ghajar, Heat and mass transfer fundamentals and applications (Fifth Edit. United States of America: McGraw-Hill Education, 2015)

22. C.D. Pe'rez-Segarra, J. Rigola, M. So`ria, A. Oliva, Int. J. Refrig. 28, 579-593 (2005)

23. www.GMCC-WELLING.com/Homeen/Product/index/classify/20.html (2018) 